\title{
El periodismo y la política: ¿dos mundos aparte? A propósito de la campaña contra Mauricio Funes
}

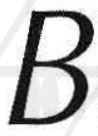

astó con que circulara el rumor de que el periodista Mauricio Funes sería uno de los candidatos presidenciales del partido FMLN para que se desatara una campaña en su contra, protagonizada, esta vez, por algunos comunicadores que abogan por una supuesta apoliticidad y neutralidad valorativa del periodismo. Lo llamativo del caso es que muchos de estos periodistas han promovido una agenda comunicativa sesgada a favor de la derecha gobernante y juzgan a Funes por su pensamiento crítico. Por otra parte, dan por sentado que Funes será el candidato del FMLN para las elecciones del 2009, aunque no hay nada oficial sobre este punto, ni por parte del Frente, ni por parte del mismo periodista, y consecuente con ello, le piden que renuncie al programa que conduce en la televisión. 
Estos periodistas, que actúan más como voceros, ideólogos y relacionistas públicos del partido oficial que como comunicadores al servicio de la sociedad salvadoreña, ven en Funes un tipo de periodismo que no se acopla a las agendas políticas e ideológicas de sus patrocinadores. En el periodista, que condujo durante años la "Entrevista al dia", ven la Némesis del periodismo sumiso al poder. Analicemos algunos de los puntos que se han puesto en evidencia en esta campaña sucia contra el periodista en cuestión.

\section{¿Dos mundos aparte?}

De los ataques contra una posible candidatura de Funes por el partido de izquierda, se desprende que sus detractores abogan por un periodismo completamente desligado de la política, como si se tratara de dos mundos aparte. Arguyen, por ejemplo, que Funes ha hecho campaña a favor de la izquierda en los espacios que ha tenido a su disposición y que ello será más evidente cuando sea formalmente candidato.

Que funes tenga un punto de vista personal sobre la situación del país no es, en absoluto, inapropiado, como tampoco lo es el que tenga opciones políticas e ideológicas. También las tienen los periodistas y sus corifeos que se han unido para atacarlo. Sólo que estas opciones son, para ellos, inatacables, porque defienden, en algunos casos de manera inconfesa, en otros, de manera ostensible, la agenda política del partido oficial y de la derecha económica, a la que consideran la única que garantiza la democracia y el desarrollo, y la más acorde con "el orden natural" de las cosas..

Acusan al periodista de tener un sesgo a favor de la izquierda, debido a la apertura que ha dado en sus programas para que distintos sectores de la vida nacional expongan, en pie de igualdad, sus argumentos acerca de los problemas que atañen al país. No le perdonan el que, por primera vez en la televisión salvadoreña, se hayan transmitido reportajes sobre la República Popular China y sobre Cuba, con el objetivo de darle a la teleaudiencia elementos de juicio para sacar sus propias conclusiones sobre la realidad de estos países. Para los actores de la campaña contra Funes, basta y sobra con los apotegmas del anticomunismo. Más imperdonable les resulta aún el que Funes se haya entrevistado con Fidel Castro y con otros representantes de la sociedad política y civil cubana, en vez de conformarse con los supuestos expertos que juzgan a Cuba desde noventa o más millas de distancia, siguiendo al pie de la letra los dictados de la política exterior estadounidense y de sus ideólogos más connotados, los cuales, por cierto, tienen amplia cabida en uno de los principales periódicos matutinos del país. 
Esto es suficiente, según ellos, para recusar las credenciales éticas y profesionales de funes y acusarlo de hacer política desde los medios. Pero la política y los medios de comunicación están en una permanente relación, puesto que éstos forman parte de la sociedad y de un contexto histórico concreto, en el que está en juego lo que va a ser del ser humano salvadoreño. La política es una dimensión intrínseca de cualquier realidad histórica, y de ella no escapan los medios de comunicación, como realidades históricas que son. Por esta razón fundamental, no puede condenarse a un periodista por tener opciones politicas y por ser considerado como un potencial candidato a la presidencia. Se supone que estamos en una sociedad en transición democrática y que uno de los mayores logros de los Acuerdos de Paz es que ahora gozamos de plenas libertades políticas ¿O no? Lo éticamente reprobable sería que un periodista aproveche la plataforma mediática de la que dispone para favorecer los intereses de los sectores de poder en el país o de un partido político en particular. Peor aún, si lo hace invocando la "neutralidad" y la "asepsia" política del periodismo, como es el caso de los detractores de Funes, que se "desgarran las vestiduras" ante su posible candidatura presidencial.

Muchos de los comunicadores que hoy se rasgan las vestiduras por que Funes llegue a ser candidato de la izquierda son los que tienen su propia agenda oculta. Sus espacios proclaman ser espacios donde hay plena libertad de expresión para todas las opciones y puntos de vista, pero cuando algunos de sus interlocutores son vistos como "opositores", ya sea políticos, sociales e incluso religiosos (pues hasta a esto han llegado), los atacan despiadadamente y tratan de desacreditarlos ante cámaras $o$ ante micrófonos.

Lo anterior es válido en el caso de quienes actúan de manera más o menos disimulada. Pero también hay quienes han hecho campaña mediática a favor del partido oficial de manera abierta. A plena luz del día, algunos de estos personajes saltan súbitamente de la sala de redacción al comando de campaña del partido oficial o a las estructuras encargadas de crear discursos e imágenes para el actual gobierno. Otros, como el caso de un ex guerrillero arrepentido que pretende imitar ilusoriamente el estilo de Vargas Llosa, participaron en la campaña de difamación contra el FMLN y su entonces candidato presidencial, Schafik Handal, impartiendo charlas, pagadas con jugosos honorarios, en diferentes centros de trabajo, buscando atemorizar a los trabajadores y empleados sobre los horrores que sobrevendrian al país con la victoria de "los comunistas". 
Para este tipo de periodismo en connivencia con el poder, pareciera que hay un completo divorcio con la ética. Tiene muchos flancos por donde ser cuestionado. Dejemos a un lado su opción partidaria. Su trabajo deja mucho que desear. Es incapaz de utilizar argumentos racionales para exponer sus puntos de vista y fundamentar racionalmente sus opciones. Es suficiente la proclamación de los viejos clisés anticomunistas, de las supuestas bondades abstractas de la libertad absoluta del mercado y la difusión del american way of thinking, aunada a difamaciones y bajezas de toda laya, para supuestamente defender las causas de la "democracia" y la "libertad". Eso no es periodismo serio, sino pura ideologización y de la más burda.

Pero por ensuciar cuartillas o usurpar espacios que podrian ser empleados para fines más nobles, como contribuir a la construcción del bien común, este "periodismo" invoca la "libertad de prensa", un concepto mal entendido y manipulado hasta el cansancio. Para dicho periodismo, libertad de prensa es abusar del poder mediático que tiene en sus manos. Cree que la libertad de prensa le hace acreedor de una libertad absoluta, una libertad sin limites, que puede pasar por encima de los derechos ajenos y de la dignidad de las personas. Según esto, la "libertad de prensa" es un bien que se puede comprar y vender. Basta con tener el suficiente poder adquisitivo para adquirir empresas mediáticas, y con ello tener el poder para calumniar, ideologizar, insultar el lenguaje y la inteligencia de las personas y ponerse al servicio de intereses espurios, en suma, para adquirir una inmunidad a la crítica ética. Como ejemplo, pueden citarse los editoriales de El Diario de Hoy, en los que se insulta, se difama y se calumnia con total impunidad a todos aquellos que mantienen una actitud crítica contra las políticas oficiales. Así, por ejemplo, se habla de los "curas de sotana roja" de la YSUCA, de "la alcohólica Procuradora", del "populacho", de "las masas enloquecidas", entre otros epítetos denigrantes. Pero el colmo es que se trata de una libertad que la sociedad debe costear. Desde hace décadas, las grandes empresas periodísticas gozan de exención de impuestos por parte del Estado, lo cual implica que la sociedad carga con los costos de unas empresas que generan ganancias a entes privados, y que se enriquecen desmedidamente con la publicidad comercial y la propaganda gubernamental, que les fluye generosamente.

Los medios de comunicación tienen una importante responsabilidad ante la sociedad a la que se deben. Tienen la responsabilidad de darle a la 
sociedad los suficientes elementos de juicio sobre los distintos problemas, para que sea la misma sociedad la que decida cómo enfrentarlos. Pero lo que estas empresas mediáticas suelen hacer es lo contrario. En vez de brindar insumos para que la ciudadanía pueda analizar críticamente su realidad y asumir conscientemente su contribución a la consolidación de una democracia real y el bienestar público, lo que pretenden es, literalmente, conducir y manipular a la "opinión pública", para orientarla a favor de los proyectos políticos y económicos de los grupos de poder.

Afortunadamente, están lejos los obscuros días en que muchos de los "periodistas" que trabajan en estos medios participaron activamente en la nefasta cadena de radio y televisión de noviembre de 1989, en la cual sentenciaron a muerte, con nombre y apellido, a opositores del gobierno, incluyendo a los mártires jesuitas. Ahora lo que hacen es presentar la realidad nacional a su manera, ideologizadamente, tanto dentro de sus espacios de comunicación como fuera de ellos.

\section{La función politica del periodismo}

No es razonable esperar que el periodismo sea ajeno a la política. El periodismo tiene una responsabilidad política, que no es lo mismo que un interés partidario. La responsabilidad política es la responsabilidad con la sociedad a la que pertenece. El periodismo cumple con dicha responsabilidad al comprometerse con los problemas del país y en su solución. El periodismo no puede, por si solo, resolver esos problemas. De eso tiene que encargarse la sociedad en su conjunto. Pero sí puede, y debe, denunciar las injusticias, vengan de donde vengan, sean del gobierno, del FMLN, o de quien sean. También debe fomentar el pluralismo y la visión crítica. Contribuir al pluralismo político, ideológico, cultural y religioso no se limita a invitar a los programas a gente representativa de las diferentes tendencias. De nada sirve hacer eso, si el conductor del espacio lo aprovecha para tratar de acorralar a quien identifique como adversario político o ideológico, y adular y consentir a los funcionarios gubernamentales y miembros del partido oficial y afines, buscando sacar adelante la agenda política de sus patronos. Se contribuye más al pluralismo y a la cultura democrática permitiendo que los distintos sectores expongan sus argumentos y los debatan públicamente, en igualdad de condiciones, contribuyendo asi, en forma efectiva, al logro de consensos para encontrar las soluciones más adecuadas a los graves problemas que padece el país.

El periodista, y por esto se ha distinguido Mauricio Funes, tiene que servir de "abogado del diablo", en el sentido de cuestionar a sus interlo- 
cutores, cuando sus argumentos - no el sector al que pertenecen, no sus ideologías, no sus personas - merecen ser mejor formulados para que los receptores de los mensajes lleguen a sus propias conclusiones, de una manera crítica y racional. Esto último es contribuir a que la sociedad se forme una visión crítica y autónoma de la realidad y se comprometa a actuar en consecuencia. Funes ha representado este tipo de periodismo, crítico, profesional y democrático, que no se compromete de lleno con una determinada postura, sino con la realidad. Es en este sentido que el periodismo cumple su función política.

Ahora bien, a sus detractores les parece escandalosa la mera posibilidad de que este periodista sea candidato presidencial. Esto no comporta ningún problema, siempre y cuando Funes, o cualquier otro periodista, de la ideología que sea, separe sus intereses partidarios de su responsabilidad profesional. Los que fustigan a Funes son los que en realidad han mezclado inmoralmente estos dos ámbitos. Han hecho política en el peor sentido: política partidaria amparándose en el ejercicio profesional y en una supuesta neutralidad y objetividad.

De todas maneras, está por verse si se oficializa la oferta del FMLN y si Funes la acepta. En el pasado, hay que tenerlo en cuenta, Funes puso unas condiciones que el partido de izquierda se negó a darle. El periodista pedía autonomía para conformar su equipo y libertad para hacer sus propuestas políticas. El FMLN optó por lo que consideraba como "seguro" y se decantó por una fórmula presidencial proveniente de sus filas. No hay garantías de que vaya a ocurrir algo distinto. Al contrario, parece que ni el FMLN ni el resto de partidos, mucho menos ARENA, están listos para procesar la libertad de pensamiento. Pero mientras haya periodistas que hacen la venia a quien tenga el poder político y economico en el pais, y partidos que requieran ese tipo de periodistas $y$ ese tipo de periodismo para mantenerse en el poder, difícilmente se podrá esperar otra cosa. Pero el trabajo periodístico de funes, que representa a muchos periodistas y muchos medios de comunicación que no están sometidos a los grandes poderes, poco a poco va creando la conciencia de compromiso ciudadano por el bien común, que necesita urgentemente la sociedad salvadoreña. 